\section{Olivier AERTS ${ }^{1}$ \\ An GOOSSENS ${ }^{2}$ \\ Françoise GIORDANO-LABADIE ${ }^{3}$}

${ }^{1}$ Department of Dermatology, University Hospital Antwerp, B-2650 Antwerp, Belgium

${ }^{2}$ Department of Dermatology,

University Hospitals K.U.Leuven,

B-3000, Leuven, Belgium

${ }^{3}$ Department of Dermatology,

Larrey University Hospital,

CHU Toulouse, 31059 Toulouse France

Reprints: F. Giordano-Labadie <giordano-labadie.f@chu-toulouse.fr>

Article accepted on 03/6/2015

\title{
Contact allergy caused by methylisothiazolinone: the Belgian-French experience
}

\begin{abstract}
The chemical Kathon $\mathrm{CG}^{\circledR}$, a mixture of the preservatives methylchloroisothiazolinone (MCI) and methylisothiazolinone (MI), was the leading cause of a worldwide epidemic of contact-allergic reactions in the eighties. From 2000 on, MI alone became allowed in industrial products and in 2005 authorities gave a green light for its use in leave-on and rinse-off cosmetics up to a maximum concentration of $100 \mathrm{ppm}(0.01 \%)$. Following initial occupational cases, a continuously increasing number of consumers sensitized to MI have been reported and both Belgian and French allergy groups decided to routinely test MI in their baseline series from 2010 onwards. Two multicenter studies, comprising 8,680 and 7,874 patients in Belgium and France respectively, both clearly show the rise in contact allergy caused by MI, with a spectacular sensitization rate of $\sim 6.0 \%$ in 2012 , even increasing to $7.0 \%$ in 2013. Mostly middle-aged women, presenting with facial-and/or hand dermatitis, were affected, although very young children were reported as well. Furthermore, the data confirmed that sensitization is primarily caused by cosmetics (mostly leave-on, but also rinse-off), household detergents and water-based paint. This unprecedented outbreak of contact sensitization to a preservative agent in Europe, and beyond, should have alerted the authorities much sooner and meanwhile the need for safer use concentrations of MI in cosmetics, detergents and industrial products is becoming more urgent every day.
\end{abstract}

Key words: methylisothiazolinone, contact dermatitis, preservative, France, Belgium, Europe
I $\mathrm{n}$ the eighties, the preservative agent Kathon $\mathrm{CG}^{\circledR}$, a mixture of methylchloro-isothiazolinone (MCI) and methylisothiazolinone (MI) in a 3:1 ratio, was the cause of a worldwide epidemic of contact-allergic reactions, with approximately $5 \%$ of the patients tested with the baseline series reacting to it. Following European legislation, which limited its use concentration in cosmetic products to a maximum of $15 \mathrm{ppm}(0.0015 \%)$ instead of the former $30 \mathrm{ppm}$, the number of cases of contact allergy dropped significantly [1]. From 2000 on, MI alone was allowed for use in industrial products, with no maximum limit set as it has weaker antimicrobial properties and was considered a weaker sensitizer. However, shortly after, the first occupational cases caused by MI in paints and glues started to appear in the literature [2]. Still convinced that MI was indeed less sensitizing than its chlorinated counterpart, the EU allowed its use up to a maximum of $100 \mathrm{ppm}$ in both leave-on (e.g. day cream) and rinse-off cosmetics (e.g. shampoo) in 2005 [3]. However, the first cosmetic cases of contact allergy appeared in 2010 [4] and since then, European alert systems (such as REVIDAL [Réseau de Vigilance en Dermato-Allergologie] in France) have highlighted an increasing number of sensitized patients. Meanwhile, dramatic sensitization rates were reported throughout Europe and the rest of the world, the highest so far coming from Finland (13.2\%) [5]. MI was even elected "Allergen of the Year" by the North-American Contact Dermatitis Society in 2013 [6]. Unfortunately, the European legislator was not in a rush to undertake the necessary regulatory action [7], although in December 2013 the Scientific Committee on Consumer Safety (SCCS), who advises the European Commission regarding cosmetic ingredients, released an Opinion stating that MI should be abandoned in leave-on cosmetics and that its use concentration in rinse-off cosmetics should be lowered to $15 \mathrm{ppm}(0.0015 \%)$ [8]. Cosmetics Europe, representing the industry, gave similar advice to its members, but only with regard to the proposal of banning MI in leave-on products [9].

The French group GERDA (Groupe d'Etudes et de Recherche en Dermato-Allergologie) and the Belgian BCEDG (Belgian Contact and Environmental Dermatitis Group) decided to collect and share their data on MI-sensitization by means of two nationwide multicenter studies $[10,11]$.

\section{The Belgian experience}

\section{Frequency of allergic reactions to the mixture of MCI/MI and to MI alone}

In the Belgian multicenter study, in which 6 university patch-test clinics and 3 private dermatologists collaborated, 
Table 1. Percentage of patients allergic to $\mathrm{MCI} / \mathrm{MI}$ and $\mathrm{MI}$ in Belgium.

\begin{tabular}{|lllll|}
\hline & $\mathbf{2 0 1 0}$ & $\mathbf{2 0 1 1}$ & $\mathbf{2 0 1 2}$ & $\mathbf{2 0 1 3}$ \\
\hline MCI/MI & $3.6 \%$ & $3.7 \%$ & $4.5 \%$ & $5.3 \%$ \\
\hline MI & $3.1 \%$ & $3.2 \%$ & $6.0 \%$ & $7.2 \%$ \\
\hline
\end{tabular}

MCI/MI: methylchloroisothiazolinone/methylisothiazolinone

MI: methylisothiazolinone

the patch test results of 8,680 patients, tested with $\mathrm{MCI} / \mathrm{MI}$ and MI between the beginning of January 2010 and the end of December 2013, were retrospectively analyzed. Additionally, the files of 6,599 patients tested in the first 3 years were analyzed in detail [11]. The study showed that in 2013 the number of patients allergic to $\mathrm{MCI} / \mathrm{MI}$ already reached over $5 \%$ and that the sensitization rate of MI even reached $7.2 \%$ (table 1). A German study had already indicated that the higher number of allergic reactions to MCI/MI could in fact be explained by sensitization to MI [12].

\section{Products causing the allergic reactions}

Both leave-on and rinse-off cosmetics were the main allergen sources and the relevance of the positive reactions to MI was considered very high (for example in 2012, approximately $80 \%$ of the reactions caused by MI were considered of "certain" or "probable" relevance, i.e. explaining the dermatitis for which the patients consulted). When analyzing the different cosmetics, some products received special attention: wet wipes (causing hand eczema as well as anogenital and perioral dermatitis), although their relative importance seemed lower in comparison with other studies; deodorants, accounting for axillary dermatitis; eye care cosmetics (e.g. hydrating creams, even when "dermatologically tested" or "for sensitive skin"), but also many rinse-off products. In certain occupations, e.g. cleaners, who may have intense skin contact with "rinse-off" products (e.g. detergents) being repeatedly in contact with the skin - hence behaving as "leave-on" products - contact dermatitis can easily be elicited and even induced [13], especially given the fact that the use concentrations of MI contained in some detergents may be rather high i.e. $>100$ ppm [14].

In the Belgian study, the number of occupational cases was rather limited and in almost half of them the main allergen source was still a cosmetic which the patient contacted at work (e.g. hand eczema caused by a shampoo in a hairdresser or a hand soap used at work). Sofa seats [15], towels and even a water bed mattress [16], contaminated by MI present in cleansing products, were also described as culprit allergen sources.

Household detergents (e.g. dish washing liquids) were pinpointed as the second major allergen source. It was found that some of them are incorrectly labeled [17], which creates a specific problem for both consumers and in the occupational environment; this was even recently reported for a medical device, i.e. an ultrasound gel [18]. Moreover, we could demonstrate that, unlike (thick) nitrile gloves, natural rubber (latex) gloves do not prevent skin penetration by $\mathrm{MI}$, hence explaining persistent hand dermatitis despite the use of so-called "protective" gloves [19]. Indeed, isothiazolinones such as MI, but also the related octylisothiazolinone
(OIT), seem to exhibit the potential of penetrating various types of materials, an observation which should be taken into account when evaluating their sensitizing potential [14].

Water-based paint used by painters but also by consumers (e. g. during renovation works at home or at the work place) may cause skin problems, usually presenting as airborne contact dermatitis, with inhalation even causing systemic contact dermatitis affecting the main body folds [20]. In strongly sensitized patients, minute concentrations of $\mathrm{MI}$ may already elicit symptoms, such as in the case of a male patient with airborne dermatitis affecting his upper eyelids, face and neck, which was caused by MI in paint used by the patients' neighbor (contact dermatitis by proxy) [21]. Usually the patients were previously sensitized to MI through the use of cosmetic products, but primary airborne sensitization could often not be excluded [22]. Water-based paint, often containing several isothiazolinone derivatives, with MI in concentrations up to $300 \mathrm{ppm}$ [1], constitutes a specific health hazard because of the long-lasting evaporation (weeks, if not months), which not only causes skin problems but also respiratory complaints [23, 24]. As isothiazolinonefree paint seems to be rarely available, proper ventilation of all painted rooms is highly recommended in order to speed up the evaporation process. Neutralization by adding sodium metabisulfite has also been proposed [23], but caution is warranted since sulfites may also cause both immediate and/or delayed allergy [25].

\section{Clinical presentation}

In our study, MI-allergy was mainly observed in women with a median age of 49 years old (women are generally overrepresented in contact allergy studies, especially when focusing on cosmetic allergy). Recently, even very young children have been reported [20]. The same observations were made in the French study, with a majority of middle-aged women being affected, and the youngest patient being only 1 year old, the latter being a troublesome feature indicating the strong sensitizing potential of MI. Indeed, alarming sensitization rates to MI in the pediatric population have started to appear in the literature [26].

The skin localizations most often reported were the face, including the eyelids (sometimes with conjunctivitis), and the hands, often with extension to the forearms, while anogenital eczema, at least in Belgium, seemed less frequent than before. Interestingly, the patients often presented with very sudden and generalized dermatitis [27], probably due to a cumulative effect caused by the use of multiple (cosmetic and other) products containing MI.

Between 2010 and 2012 almost 1 out of 10 patients suffered from airborne contact dermatitis, almost always caused by MI in water-based paint. No respiratory complaints were observed, although reported [28]. Of note, isothiazolinones can cause unusual clinical manifestations such as lupus-like skin lesions [29], urticaria [30], or even mimic cutaneous T-cell lymphoma [31]. Interestingly, MI can also act as a relevant sensitizer at the mucosal level, for example in the anogenital region, due to the use of sexual lubricants or wet wipes [11], and also at the oral mucosa [14].

In 3 of our patients, the clinical and histological examination suggested a drug eruption, but in fact MI contact allergy was the correct final diagnosis. Another patient, 


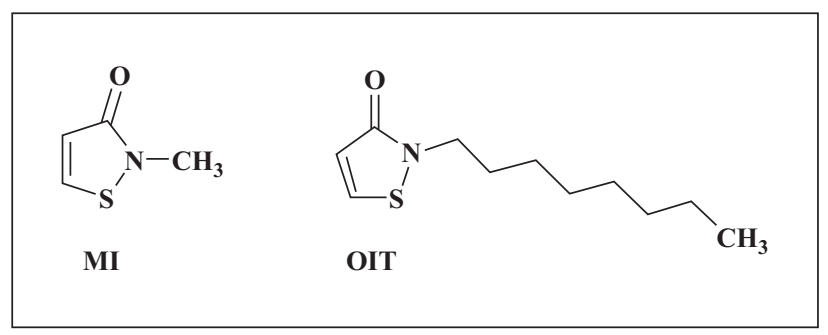

Figure 1. Chemical structure of methylisothiazolinone (MI) and octylisothiazolinone (OIT).

a painter, consulted for a photo-aggravated dermatosis following airborne contact with MI-containing paint [11], an observation which was recently confirmed by French dermatologists (Dr. Brigitte Milpied-Homsi, personal communication, REVIDAL meeting, 13 January 2013, Paris).

\section{How to test correctly for MCI/MI- and MI-contact allergy}

Both the Belgian and French studies showed that patch testing with $\mathrm{MCI} / \mathrm{MI}$ at $100 \mathrm{ppm}(0 ; 01)$ aqueous solution, as formerly present in the European baseline series, is insufficient to detect contact allergy to MI, and that a higher concentration is absolutely necessary. Indeed, it was calculated that $36.2 \%$ of patients in Belgium (i.e. more than 1 out of 3) would otherwise not have been correctly diagnosed. Recently, the European Society for Contact Dermatitis (ESCD) has recommended the inclusion of MI $2000 \mathrm{ppm}(0.2 \%)$ aq. in the European baseline series [32]. Likewise, MCI/MI should be tested at $200 \mathrm{ppm}(0.02 \%)$ aq., as recently recommended as well [33], to avoid missing allergy to the chlorinated derivative. However, it should be mentioned that these higher test concentrations should be applied using a micropipette $(15 \mu \mathrm{L}$ for a Finn Chamber or $20 \mu \mathrm{L}$ for a Chemotechnique Chamber) in order to prevent active sensitization. If not available, it is safer to use MCI/MI $100 \mathrm{ppm}(0.01 \%)$ and MI $500 \mathrm{ppm}(0.05 \%)$, bearing in mind that false-negative reactions might occur.

\section{And what about the other isothiazolinones?}

Cross-reactivity between the different isothiazolinone derivatives has been poorly studied (e.g. [34]). OIT, the most chemically-related substance to MI (figure 1), gained attention in the Belgian study: approximately $40 \%$ of the patients positive to OIT, and for whom no relevant OITcontaining allergen source could be found, were primarily sensitized to cosmetics containing MI and hence showed a possible (partial) cross-reaction to OIT. On the contrary, benzisothiazolinone (BIT) did not seem to cross-react with MI. Finally, it was also reported that some cosmetic products might "illegally" contain OIT or BIT [35].

\section{The French experience}

The main objective of this study [10] was to describe the evolution of the sensitization rate to MI in patients tested for suspected contact dermatitis in France between 2010 and 2012.

This was a multicenter, retrospective, report-based study of all cases observed from January 2010 to December 2012 and reported by French private or hospital-based dermatologists, all members of the Revidal-Gerda group. During this period, patch tests with MI were systematically performed and all cases of MI-sensitization were collected, thereby specifying age, sex, clinical relevance and concomitant sensitization to MCI/MI for each positive test result. If possible, the product(s) responsible for inducing the allergic contact dermatitis and the patient's occupation were specified.

\section{Results}

The data from 16 French centers, comprising 7,874 patients patch tested with MI alone in the aforementioned period, were analyzed.

In most cases, the test concentration of MI was $200 \mathrm{ppm}$ aq. (69-72\% of cases) or $500 \mathrm{ppm}$ aq. (21-29\%), while only one center used 2000 ppm aq. in 2011 and 2012. The mixture of MCI/MI was always tested at $100 \mathrm{ppm}$ aq.

Patch-test results showed that the proportion of MI-positive tests more than tripled in 3 years, rising from $1.50 \%$ (95\% CI $0.93-1.92$ ) to $3.26 \%$ (95\% CI 2.62-4.05\%) and even further to $5.56 \%$ (95\% CI 4.50-9.49\%) in 2010, 2011 and 2012, respectively.

Positive tests were found to be relevant in $87.5 \%, 80.2 \%$ and $90.3 \%$ of cases in 2010, 2011 and 2012, respectively.

The analysis of the study population showed that women accounted for most cases of MI-sensitization $(75 \%, 69.8 \%$ and 77.8\% of MI-positive patients in 2010, 2011 and 2012, respectively) whereas the median age was between 39 and 43 years with a range of 1 to 88 years.

Among the MI-positive patients, MCI/MI remained negative in $29.2 \%, 32.6 \%$ and $33.5 \%$ of cases in 2010, 2011 and 2012 , respectively, which corresponds to approximately a third of false-negative results with the MCI/MI test among patients allergic to MI.

Over the three years, information about the culprit MIcontaining products was available for $83.7 \%$ (247/295) of the positively-reacting patients. Among these, at least one product was held responsible for the allergic contact dermatitis in the majority of cases, i.e. 83.4\% (206/247), although in some patients up to 4 MI-containing products were found as the cause of their allergic contact dermatitis. Overall, a total of 245 products were involved. Cosmetic products accounted for $73.1 \%$ (179/245) and among these most were rinse-off products, mainly soaps (particularly industrial soaps), other cleansing and hair-care products. Household products represented $16.7 \%$ (41/245) with most of them being dishwashing liquids. Finally, industrial products represented $6.5 \%$ (16/245), mainly cutting oils followed by paint.

\section{A generalized epidemic throughout Europe}

The French study also showed that the proportion of positive tests to MI had increased significantly from 2010 to 2012 
Table 2. Current prevalence and increase of the sensitization rate to MI in 8 European countries.

\begin{tabular}{|c|c|c|c|c|c|c|c|c|}
\hline COUNTRY & $\begin{array}{l}\text { FRANCE } \\
\text { (10) }\end{array}$ & $\begin{array}{l}\text { BELGIUM } \\
\text { (11) }\end{array}$ & $\begin{array}{l}\text { GERMANY } \\
\text { (13) }\end{array}$ & $\begin{array}{l}\text { SWEDEN } \\
(37)\end{array}$ & $\begin{array}{l}\text { DENMARK } \\
\text { (38) }\end{array}$ & $\begin{array}{l}\text { PORTUGAL } \\
\text { (39) }\end{array}$ & $\begin{array}{l}\text { BRITISH } \\
\text { ISLES } \\
(40)\end{array}$ & $\begin{array}{l}\text { FINLAND } \\
\text { (5) }\end{array}$ \\
\hline $\begin{array}{l}\text { Prevalence } \\
\text { in \% } \\
\text { (year) }\end{array}$ & $\begin{array}{l}5.6 \% \\
(2012)\end{array}$ & $\begin{array}{l}7.2 \% \\
(2012)\end{array}$ & $\begin{array}{l}6 \% \\
(2012)\end{array}$ & $\begin{array}{l}6.5 \% \\
(2012)\end{array}$ & $\begin{array}{l}6.5 \% \\
(2013)\end{array}$ & $\begin{array}{l}10.9 \% \\
(2013)\end{array}$ & $\begin{array}{l}11.1 \% \\
(2013)\end{array}$ & $\begin{array}{l}13.2 \% \\
(2013)\end{array}$ \\
\hline $\begin{array}{l}\text { Increase of } \\
\text { sensitization } \\
\text { rate } \\
\text { (period) }\end{array}$ & $\begin{array}{l}+4.8 \\
(2010-2012)\end{array}$ & $\begin{array}{l}+4.1 \\
(2010-2012)\end{array}$ & $\begin{array}{l}+4.1 \\
(2009-2012)\end{array}$ & $\begin{array}{l}+3.6 \\
(2010-2012)\end{array}$ & $\begin{array}{l}+1.7 \\
(2011-2013)\end{array}$ & $\begin{array}{l}+5.8 \\
(2012-2013)\end{array}$ & $\begin{array}{l}+9.4 \\
(2010-2013)\end{array}$ & $\begin{array}{l}+2.3 \\
(2012-2013\end{array}$ \\
\hline $\begin{array}{l}\text { MI-test } \\
\text { concentration } \\
\text { (ppm) }\end{array}$ & $200-500$ & $\begin{array}{l}200-500 \\
\text { (1000 K.U. } \\
\text { Leuven) }\end{array}$ & 500 & 2000 & 2000 & 500 & $200-2000$ & 500 \\
\hline
\end{tabular}

and that, among the patients tested for suspected allergic contact dermatitis, $5.6 \%$ were sensitized to MI.

Similar observations were made in other European studies in which MI was systematically tested (table 2).

Thus, in Germany, the IVDK (Information Network of Departments of Dermatology for the surveillance and scientific evaluation of contact allergies) reported an increase in the proportion of MI-positive tests (with MI tested at 500 ppm aq.) from $1.9 \%$ to $4.4 \%$ between 2009 and 2011 and reaching 6.0\% in 2012 [13]. In the United Kingdom, the study by Mc Fadden et al. [36] found 5.7\% of MI-sensitized patients in 2012 versus $0.5 \%$ in 2010 with a 500 ppm aq. test concentration.

In Sweden, Isaksson reported that the contact allergy rate for MI increased from 2.9\% in 2010 to $6.5 \%$ in 2012 [37]. In his study in Denmark, Madsen reported $6.5 \%$ of MIsensitized patients in 2013 versus $4.8 \%$ in 2011 [38]. In Portugal, Gameiro et al. observed a significant increase in isothiazolinone-sensitization (MI tested at $500 \mathrm{ppm}$ aq. and $\mathrm{MCI} / \mathrm{MI}$ at $100 \mathrm{ppm}$ aq.) with a rate of $5.15 \%$ in 2012 that more than doubled to $10.9 \%$ in 2013 [39].

According to the report of the British Society for Cutaneous Allergy (BCSA), published by Johnson [40], in the British Isles, $11.1 \%$ of patients had a positive patch test reaction to MI in 2013 versus $1.7 \%$ in 2010.

Finally, Finland holds the European record with 13.2\% of MI-sensitized patients in 2013 versus $10.3 \%$ in 2012 according to the study by Lammintausta et al. [5].

Some epidemiological methods have been used to assess the prevalence of contact allergy in the general population by extrapolating from clinical data called CE-DUR (Clinical Epidemiology and Drug Utilisation Research) data [41]. This tool estimates that a prevalence of contact allergy to an allergen of $6 \%$ in centers specialized in contact allergy corresponds to a prevalence of over $1 \%$ in the general population and could thus be categorized as a "generalized" epidemic.

Thus, at this time we can definitely state that there is a real epidemic of MI contact allergy in Europe.

\section{Conclusions}

Although our studies have their limitations, in part due to their multicenter and retrospective design, they both clearly show the rise in contact allergy caused by MI in Belgium and France, with a spectacular sensitization rate of $\sim 6,0 \%$ in 2012; in 2013 up to $7.0 \%$ in Belgium and even $10 \%$ or more in some other European countries $[5,39,40]$.

Furthermore, the present studies have even underestimated the true MI-epidemic given the fact that patch tests were not always performed with the most optimal patch-test concentrations.

Our data also confirm that sensitization is primarily caused by cosmetic products, in particular by wet wipes, deodorants and skin care products, but also by rinse-off cosmetics such as shampoos and soaps. Household detergents constitute the second most important allergen source, followed by water-based paint, the latter causing airborne and sometimes systemic dermatitis.

In order to correctly diagnose contact allergy caused by $\mathrm{MCI}$ and $\mathrm{MI}$ it is of utmost importance to include MCI/MI 200 ppm aq. (instead of $100 \mathrm{ppm}$ aq.) and MI 500 ppm aq., preferably even $2000 \mathrm{ppm}$ aq., if a micropipette is available, in the European baseline series.

European authorities should urgently regulate safer use concentrations of MI, not only by banning its use in leave-on cosmetics, but also by lowering the maximum permitted concentration in rinse-off cosmetics, household and industrial products.

Although the cosmetic industry has already advised its members to phase out the use of MI in leaveon products, the future will tell how fast this will happen and how this will affect the devastating sensitization rates that are currently still being reported. Likewise, one might consider further lowering the presently allowed use concentration of the mixture of MCI/MI (i.e. $15 \mathrm{ppm}$ ), which is nowadays still used in a large variety of rinse-off (and even leave-on) cosmetics! However, its presence in leave-on cosmetics will be prohibited from 16/04/2016 onwards as regulated by the EU [42].

Last but not least, future studies still need to be carried out and might focus on (i) cross-reactions between the different isothiazolinones, (ii) unusual clinical manifestations, including respiratory complaints, which probably remained underestimated in our studies, and (iii) the real use concentrations of isothiazolinones in cosmetic products, since some studies suggest that these may not always be correct $[35,43]$. 
This review article is part of a series of papers published by experts from GERDA, the French study and research group on contact dermatitis

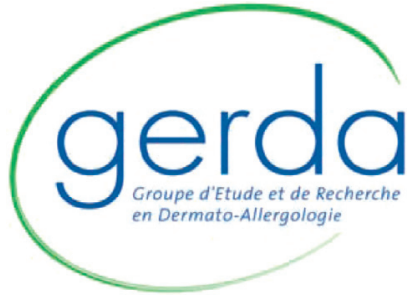

Disclosure. Financial support: none. Conflict of interest: none.

\section{References}

1. Lundov MD, Krongaard T, Menné TL, et al. Methylisothiazolinone contact allergy: a review. Br J Dermatol 2011 ; 165: 1178-82.

2. Isaksson $M$, Gruvberger $B, B$ ruze $M$. Occupational contact allergy and dermatitis from methylisothiazolinone after contact with wallcovering glue and after a chemical burn from a biocide. Dermatitis 2004; 15: 201-5.

3. Burnett $\mathrm{CL}$, Bergfeld WF, Belsito DV, et al. Final report of the safety assessment of methylisothiazolinone. Int J Toxicol 2010;29: 187S2135 .

4. Garcia-Gavin J, Vansina S, Kerre S, et al. Methylisothiazolinone, an emerging allergen in cosmetics? Contact Dermatitis 2010; 63: 96-101.

5. Lammintausta K, Aalto-Korte K, Ackerman L, et al. An epidemic of contact allergy to methylisothiazolinone in Finland. Contact Dermatitis 2014; 70: 183-92.

6. Castanedo-Tardana MP, Zug KA. Methylisothiazolinone. Dermatitis 2013; 24: 2-6

7. Gonçalo M, Goossens A. Whilst Rome Burns: The epidemic of contact allergy to methylisothiazolinone. Contact Dermatitis 2013; 68: 257-8.

8. Scientific Committee on Consumer Safety (2006), DG Sanco European Commission. Opinion on methylisothiazolinone (P94) submission II (sensitisation only), Adopted on 12 December 2013. Available at: http://ec.europa.eu/health/scientific_committees/consumer_safety/ docs/sccs_o_145.pdf (last accessed 24 February 2014).

9. Cosmetics Europe 2013. Cosmetics Europe issues recommendation to discontinue use of MIT in leave-on cosmetic products, 13 December 2013. Available at https://www.cosmeticseurope.eu/news-aevents/news/647-cosmetics-europe-recommendation-on-mit.html (last accessed 24 February 2014).

10. Hosteing S, Meyer N, Waton J, et al. Outbreak of contact sensitization to methylisothiazolinone: an analysis of French data from the REVIDAL-GERDA network. Contact Dermatitis 2014; 70: 262-9.

11. Aerts $O$, Baeck $M$, Constandt $L$, et al. The dramatic increase in the rate of methylisothiazolinone contact allergy in Belgium: a multicentre study. Contact Dermatitis 2014. doi: 10.1111/cod.12249.

12. Geier J, Lessmann $H$, Schnuch $A$, et al. Recent increase in allergic reactions to methylchloroisothiazolinone/methylisothiazolinone: is methylisothiazolinone the culprit? Contact Dermatitis 2012; 67:33441.

13. Uter W, Geier J, Baver A, et al. Risk factors associated with methylisothiazolinone contact sensitization. Contact Dermatitis 2013;69: 231-8

14. Aerts $\mathrm{O}, \mathrm{Meert} H$, Janssens $S$, et al. A sudden flare-up of a quiescent oral lichen planus: methylisothiazolinone as the prime suspect? Contact Dermatitis 2015; 72: 186-9.
15. Vandevenne A, Vanden Broecke K, Goossens A. Sofa dermatitis causedby methylisothiazolinone in a leather-care product. Contact Dermatitis 2014;71:111-3. doi: 10.1111/cod.12253.

16. Vandevenne A, Goossens A, Verreycken E, et al. Dermite de contacto alérgica ao metilcloro- e metilisotiazolinona numa cama de água? Allergic contact dermatitis from methylchloro- and methylisothiazolinone from a waterbed? Journal of the Portuguese Society of Dermatology and Venereology 2012; 70: 223-5.

17. Vanneste L, Persson L, Zimerson E, et al. Allergic contact dermatitis caused by methylisothiazolinone from different sources, including 'mislabelled' household wet wipes. Contact Dermatitis 2013; 69: 31 1-2.

18. Madsen JT, Broesby-Olsen S, Andersen KE . Undisclosed methylisothiazolinone in an ultrasound gel causing occupational allergic contact dermatitis. Contact Dermatitis 2014;71:312-3. doi: 10.1111 /cod. 12282 .

19. Espasandín Arias $M$, Goossens A. Natural rubber gloves might not protect against skin penetration of methylisothiazolinone. Contact Dermatitis 2014;70: 249-51.

20. Aerts $O$, Cattaert $N$, Lambert J, et al. Airborne and systemic dermatitis, mimicking atopic dermatitis, caused by methylisothiazolinone in a young child. Contact Dermatitis 2013; 68: 250-6.

21. Horst N, Lambert J, Aerts O. Aërogeen contacteczeem door methylisothiazolinone. Ned Tijdschr Dermatol Venereol 2013; 23: 324-6.

22. Kaae J, Menné TL, Thyssen JP. Presumed primary contact sensitization to methylisothiazolinone from paint: a chemical that became airborne. Contact Dermatitis 2012; 66:340-55.

23. Bohn S, Niederer M, Brehm K, Bircher AJ. Airborne contact dermatitis from methylchloroisothiazolinone in wall paint. Abolition of symptoms by chemical allergen inactivation. Contact Dermatitis 2000; 42: 196-201.

24. Lundov $M D$, Kolarik $B$, Bossi $R$, et al. Emission of isothiazolinones from water-based paints. Environ Sci Technol 2014; 48: 6989-94. doi: 10.1021 /es500236m

25. García-Gavín J, Parente J, Goossens A. Allergic contact dermatitis caused by sodium metabisulfite: a challenging allergen. A case series and literature review. Contact Dermatitis 2012; 67:260-9.

26. Patel AN, Wootton $\mathrm{Cl}$ AN, English JS. Methylisothiazolinone allergy in the paediatric population: the epidemic begins? $\mathrm{Br}$ J Dermatol 2014; 170: 1200-1.

27. Bregnbak $D$, Lundov $M D$, Zachariae $C$, et al. Five cases of severe chronic dermatitis caused by isothiazolinones. Contact Dermatitis 2013; 69: 57-9.

28. Lundov MD, Zachariae $C$, Menné $T L$, et al. Airborne exposure to preservative methylisothiazolinone causes severe allergic reactions. BM. 2012 Dec 4; 345: e8221. doi: 10.1136/bmi.e8221.

29. Morren MA, Dooms-Goossens A, Delabie J, et al. Contact allergy to isothiazolinone derivatives: unusual clinical presentations. Dermatology 1992; 184: 260-4.

30. Gebhardt M, Looks A, Hipler UC. Urticaria caused by type IV sensitization to isothiazolinones. Contact Dermatitis 1997; 36: 314 .

31. Knackstedt TJ, Zug KA. T-cel lymphomatoid contact dermatitis : a challenging case and review of the literature. Contact Dermatitis 2015; 72: 65-74

32. Bruze $M$, Engfeldt $M$, Gonçalo $M$, et al. Recommendation to include methylisothiazolinone in the European baseline patch test series - on behalf of the European Society of Contact Dermatitis and the European Environmental and Contact Dermatitis Research Group. Contact Dermatitis 2013; 69: 263-70.

33. Bruze $M$, Goossens A, Isaksson $M$. Recommendation to increase the test concentration of methylchloroisothiazolinone/methylisothiazolinone in the European baseline patch test series - on behalf of the European Society of Contact Dermatitis and the European Environmental and Contact Dermatitis Research Group. Contact Dermatitis 2014; 71: 35-40.

34. Geier J, Schnuch A. No cross-sensitization between $\mathrm{MCl} / \mathrm{Ml}$, benzisothiazolinone and octylisothiazolinone. Contact Dermatitis 1996; 34: 148 .

35. Alvarez-Rivera $G$, Dagnac $T$, Lores $M$, et al. Determination of isothiazolinone preservatives in cosmetics and household products by matrix solid-phase dispersion followed by high-performance 
liquid chromatography-tandem mass spectrometry. J Chromatogr A 2012; 1270: 41-50.

36. McFadden JP, Mann J, White JML, et al. Outbreak of methylisothiazolinone allergy targeting those aged $\geq 40$ years. Contact Dermatitis 2013; 69: 53-5

37. Isaksson $M$, Hauksson I, Hindsén $M$, et al. Methylisothiazolinone Contact Allergy is Rising to Alarming Heights Also in Southern Sweden. Acta Derm Venereol 2015; 95: 31-4.

38. Madsen JT, Andersen KE. Further evidence of the methylisothiazolinone epidemic. Contact Dermatitis. 2014; 70: 246-7.

39. Gameiro A, Coutinho I, Ramos L, Gonçalo M. Methylisothiazolinone: second 'epidemic' of isothiazolinone sensitization. Contact Dermatitis 2014; 70: 242-3.
40. Johnston GA, \& contributing members of British society for Cutaneous Allergy (BSCA). The rise in prevalence of contact allergy to methylisothiazolinone in the British Isles. Contact Dermatitis 2014; 70: 238-40.

41. Thyssen JP, Menné T, Schnuch A, et al. Acceptable risk of contact allergy in the general population assessed by CE-DUR-a method to detect and categorize contact allergy epidemics based on patient data. Regul Toxicol Pharmacol 2009; 54: $183-7$.

42. Commission Regulation (EU) No $1003 / 2014$ of 18 September 2014. Official Journal of the European Union 26.9.201; L 282/1-4. 43. Horev $L$, Isaksson $M$, Engfeldt $M$, et al. Preservatives in cosmetics in the Israeli market conform well to the European legislation. J Eur Acad Dermatol Venereol 2015;29:761-6. 